\title{
Is There Something in Common? Forms and the Theory of Word Meaning"
}

\author{
Forthcoming in the European Journal of Philosophy
}

\begin{abstract}
Plato's reflections on Forms have generally been overlooked, in contemporary Philosophy of Language, as a serious resource for illuminating the notion of word meaning. In part, this is due to the influence of Wittgenstein's critical reflections on looking for 'something in common' as explanatory for use of a general term. I argue that, far from being undermined, appeal to Forms can both help explain, and provide corrective critical insight into, Wittgenstein's observations. Plato's reflections provide insight into word meaning that is relevant for contemporary research. Relevant considerations include: (1) explanation as to why an item is F; (2) looking to 'what something is'; (3) the compresence of opposites; (4) whether participation in a Form involves approximation to the Form.
\end{abstract}

Wittgenstein writes in the Blue Book that we have a mistaken tendency to 'look for something in common to all the entities which we commonly subsume under a general term', with this commonality being 'the justification for applying the general term' to those entities (1972, p. 17). Wittgenstein suggests that there may be no such commonality. The point is repeated in the Philosophical Investigations. If you look at different games, 'you will not see something that is common to all, but similarities, relationships, and a whole series at that' $(1953, \S 66)$. If this is true, appeal to something in common should not be the basis for an account of how we use general terms.

Wittgenstein's position is sometimes taken to undermine a picture of predication that arises from Plato's discussions of Forms. ${ }^{1}$ Some passages in Plato indicate the following: at least some words can be associated with a Form, and all the items to which the word truly applies are items that participate in that Form (Phaedo 78d-e; 102b-103c; Republic 596a; Parmenides 130e-131a; Phaedrus 238a). This suggests an account in which a 'something in common' explains the use of a word.

In spite of initial appearances, it does not directly follow that there need be a conflict between Wittgenstein's discussion and Plato's account of the Forms. It may depend on the type of commonality that we are looking for. Richman (1962) observed that what counts as 'something common' (Wittgesntein's phrase) is open to interpretation, and concludes:

When we look once more at the question: Do (must) the referents of a general term have something common? ... it does not seem to me that the notion of 'something common' is clear enough to indicate that a negative answer to the question is justified. (p. 830)

\footnotetext{
* I would in particular like to thank M. M. McCabe for encouragement and for extensive comments on a first draft of the paper. The paper has also been significantly improved by criticisms of an earlier draft that a referee for this journal provided.

${ }^{1}$ Forster says that Wittgenstein wants to establish 'that a certain theory about the nature of all general concepts that was first propounded by Plato ... is mistaken', and Forster thinks that this project of Wittgenstein's is 'basically correct and extremely important' (2010, pp. 71, 72).
} 
Wittgenstein does not usually discuss what notion of commonality he has mind, but he does provide a hint in the Blue Book. He compares the quest for an explanatory common property with an attitude that thinks of properties as ingredients of the things which have the properties ... as alcohol is of beer and wine' (1972, p. 17). The analogy suggests an attitude in which properties are thought of as independently identifiable elements that play a role in making up a particular whole. Suppose that when a general term ' $F$ ' is correctly applied to an item that item can be said to have the property of being F. If properties are thought of as ingredients, application of the term ' $F$ ' to multiple items should correlate with a common element that is found in the make up of those items. Wittgenstein denies that any such commonality need be in place to account for our use of general terms.

But Plato likewise, as I will show, recognized that groupings marked by general terms need not be characterized by shared ingredients. He explicitly allows for the fact that items named by a general term may vary 'in every sort of way [pantoiōs]' (Republic VI 484b), and can be 'in some way even quite unlike each other', even 'contrary' [enantias] to each other (Philebus 12c, 13a). Plato's account of the Forms is in fact explanatory of this observation, rather than being challenged by it. In addition, his discussions, as I will also show, suggest a way in which Wittgenstein's account falls short of providing an adequate account of our use of words.

It is not clear that Plato saw Forms as explanatory of words in general (see Harte 2011, pp. 196-201), so we cannot straightforwardly claim that Plato was looking to provide a general account of predication. Plato's interests, in general, are not focused on words but on the way the world is. ${ }^{2}$ Independently, though, of the original scope that Plato intended for the explanatory role of Forms, his discussions provide significantly interesting resources that can be applied to an explanation of our use of words in language. This is because how we understand a word can be construed in terms of how something has to be in order for the word to apply.

Contemporary Philosophy of Language has, though, largely ignored Plato's discussions of Forms. This is a serious oversight, especially given that the topic of word meaning, though central to our understanding of language, remains underdeveloped. Pietroski, for example, has written that the 'right conception of linguistic meaning may still be undreamt of'. ${ }^{3}$ There are several aspects of Plato's discussion that can be applied to a linguistically oriented thesis: (1) the type of explanation relevant to a question as to why an item is tall, beautiful, or whatever; (2) looking to 'what something is'; (3) the compresence of opposites; (4) whether participation in a Form involves approximation to the Form. I discuss these in sections $1-4,{ }^{4}$ and I finish with a critical reflection on an aspect of Wittgenstein's discussion in section 5.

\footnotetext{
${ }^{2}$ Thanks to M.M. McCabe for stressing this (p.c.). Nehamas 1979, p. 102 does suggest that one of the central purposes of the theory of Forms was that of articulating 'the very concept of predication', and Bostock 1986 suggests that Plato had word meanings in mind when discussing Forms. Even if such claims are too strong, it remains the case that many of the things that Plato said about the Forms apply, with intriguing relevance, to the topic of word meaning

${ }^{3}$ Pietroski 2005 , p. 271 . Recanati likewise comments that 'nearly everything is up for grabs' $(2010, \mathrm{p}$. 18).

${ }^{4}$ Other issues, such as the Third Man argument and self-predication, or separation and/or immanence, are not relevant for my focus. Following much scholarship, I treat Plato's discussion of the Forms as an evolving series of reflections rather than a set 'theory' as such, though (see White 1992) I do not suppose that Plato fundamentally changed his views.
} 


\section{Explanation for why $x$ is $F$}

If we are asked to do something immediately, we may ask (or wonder) what 'immediately' means in that instance. If it is an instruction to put our pens down in an exam, it might mean within the next two seconds. If it is an instruction to begin cooking a meal, it might mean in the next few minutes. If it is a publisher telling us we need to finish a novel, it might mean in the next few days. Similar clarifications may be relevant for other words. We may ask what is meant by the claim that someone is tall (the point may be that the person is seven feet tall), or that cycling on roads is dangerous (the point may be that you are basically unprotected while moving within inches of traffic), and so on. Different instances may elicit different answers as to what is being conveyed by a given word.

These are all answers to what is meant by a use of a word or phrase. They focus on an instance, or type of instance, that will appropriately manifest the condition that the word was used to express. The appropriate manifestation can vary in different instances, and in this sense what the word 'means' - what it is used to convey - can vary.

But in another sense, these are not answers to the question of what a word means. 'Immediately' does not, per se, mean any particular time interval, nor 'tall' some particular height, nor 'dangerous' some particular situation. In this other sense, the perspective is on 'meaning' qua that which constitutes the appreciation of a word that separates English speakers from those who do not speak English and that is pre-theoretically expressed as 'knowing what the word means'. The perspective is not on an assessment of what a word has been used to convey in a given instance - an assessment that may differ between those who know English - but on the initial grasp of a word that initiates the process of comprehension.

Moravcsik makes this point using the example 'emergency'. A professor is leaving for abroad and tells the secretary not to ring except in case of an emergency.

I take it that, at this point, both the professor and his secretary understand the meaning of 'emergency'. Nevertheless, further discussion is called for. ... [I]n this case we need to supplement the discussion with having Professor Jones say something like: 'By "emergency" I mean here things like an earthquake, injury to my children, the university going bankrupt, etc.' Even if both Professor Jones and his secretary understand English perfectly, it is informative for Professor Jones to add this. (Moravcsik 1990, 252)

What is at stake here is not the understanding of English but the particular force with which 'emergency' is used in this instance. At least prima facie, these appear to be two different notions of word meaning. An answer to what is meant by a word does not look as though it gives an answer to what constitutes the understanding of a word that English speakers possess.

Something very similar to this distinction is found in Plato. In the Phaedo (96ff.) Socrates explains how in his youth he had looked to natural science for the aitiai (often translated, a bit misleadingly, by 'causes') of everything. The use of aitia here indicates some type of explanation, something that answers a 'why' question, but where the type of answer can be much broader than our contemporary notion of cause (see Vlastos 1969; Sedley 1998; Politis 2010). The type of answer - the type of explanation, or aitia - that is in view can be illustrated from Hippias Major 294a-b: 
we were looking for that by which $[h \bar{o}(i)]$ all beautiful things are beautiful—like that by which $[h \bar{o}(i)]$ all large things are large, that is, by exceeding [tō(i) huperechonti].

That 'by which', or because of which, all large things are large is by exceeding (something else). This type of reason need not make reference to the dimensions that, in a sense, make a person tall, nor to the biological cause for why that person is tall. There is, beyond these other types of explanation, a further explanation in which it is the exceeding of normal height that is explanatory of why 'large' is predicated of that person.

When Socrates says that he had looked, in his youth, to natural science for explanation [aitia], his examples indicate that he now sees himself as having looked for the wrong type of explanation. Socrates had thought it was appropriate to say that a tall man was taller than a small man 'by a head' [tē(i) kephalē(i)] (Phaedo 96e), as if to say that the extra head-length was the explanation for why the man is described as tall. But, in a converse case to the one Wittgenstein discussed, this common factor can also account for why someone is a small man - they are shorter 'by a head' (Phaedo 101a). This undermines the claim that this type of statement, as to why someone is tall (or short), is appropriate for the explanation of tallness (or shortness) that Plato is looking for. ${ }^{5}$

Similar considerations are brought to bear on the explanation for why something is beautiful:

if someone tells me that a thing is beautiful because it has a bright color or shape or any such thing, I ignore these other reasons - for all these confuse me. (Phaedo 100cd; cf. Republic 476b, 480a)

A particular colour or shape, while it may in a sense be responsible for an item's appearing beautiful, may in other items be what contributes to making those items ugly: gold may make some things beautiful but not if the setting is inappropriate (Hippias Major 289e-290d). Just as a head-length is not itself the explanation of tallness or shortness, neither is a particular colour (or whatever) the explanation of beauty or ugliness.

In this context, Plato asserts that the only true explanation for beauty, or bigness (etc.), will be beauty itself, or bigness itself (Phaedo 100-101). I suggest that this, in part, is to say that an explanation of beauty or bigness will not be constructed in terms of the concretely manifested parts that happen, in a given case, to characterize the item to which predications of beauty or bigness are applied. In terms of such parts, it is plausible to suggest that there could be such variability in how a property is manifested that the claim of no common ingredient, between items named by a general term, will be justified. ${ }^{6}$

To illustrate how, even so, there can be a commonality between items labeled by a general term, we can consider Plato's suggestion that there is a level of explanation, relating to the property of being large, which relates not to particular heights or efficient causes but to exceeding. While this is not complete as an account of the basis for our use of the word

\footnotetext{
${ }^{5}$ As Irwin puts it, a property $G$ cannot be the explanation of x's being F 'if either (1) G is present in y, but $y$ is not F, or (2) G is not present in z, but z is F' (1995, p. 155; cf. p. 159; and see Nehamas 1979; Politis 2010).

${ }^{6}$ Ide 2002 suggests that a key problem addressed in the Philebus is: 'given a single account of being F, how could different F's have different properties in virtue of being F? The only possible answer is that they have different properties because they satisfy the single account in different ways' (p. 266; cf. Harte 2002, pp. 177ff. For an example, see Hoyningen-Huene 2015 on the term 'refinement').
} 
'large'-not all dimensions along which something can exceed another thing relate to largeness - it does indicate a partial and informative type of explanation. An ant that exceeds typical ant size may be a large ant, and a building that exceeds typical building size may be a large building. In appropriate contexts, almost any piece of physical reality can be correctly described as large. There is no motivation to search for an ingredient, common to (almost) every portion of physical reality, as explanatory of why 'large' may be correctly applied to those portions. This, though, is consistent with ascribing the property of being large to any item of which 'large' is correctly used, with this use based on the common factor of exceeding.

Suppose that explanation began, contrary to the picture I have just given, with the aitiai that Socrates wishes to set aside as inappropriate to the 'why is it F' question, namely, the explanations couched in terms of the particular manifestations, or types of manifestation, that instantiate examples of F-ness in different cases (see Wolfsdorf 2003). The associated notion of word understanding would presumably be based on familiarity with those instances, with application of a term to new instances based on the presence of an appropriate similarity between the new instances and those already correctly described with ' $F$ '. Such an account is partially endorsed by Recanati (2004, pp. 146-151) under the label of 'meaning eliminativism' (Recanati relates this approach to Wittgenstein). This is an account that explains word use on the basis of a knowledge of 'source situations' (previous uses) and judgements of similarity to those previous uses. In effect, the question of word understanding that corresponds to the pre-theoretic notion of 'what the word means' is being answered in terms of a compendium of answers to what is meant 'by' a word. Familiarity with previous uses - the instances to which the term has been applied - is implicitly taken as constituting the basis of understanding.

In contrast, by looking to a type of question that is not properly answered in terms of the instances that manifest a given property, Plato indicates that there is an alternative type of explanation. This is a pointer to how we should consider our understanding of words, and it relates to the notion of a Form.

\section{The seal of 'what it is'}

Plato makes repeated use of the semi-technical phrase 'what is F' [ho estin F], or sometimes simply 'what is' [ho estin] (see Adomello 2013). It is used in special respect of the Forms, indicating in some sense the true nature of something. That which is 'equal itself', as opposed to a particular instance of equal items, is the Form, 'the what is equal' [to ho estin ison] (Phaedo 74d). To talk about what a bed really is is to talk about that 'upon which we set this seal, "what is" ...' (Phaedo 75c-d; cf. 92d-e). For my purposes, I will illustrate what may be in mind here by considering a bed, as discussed at Republic X 596e. There is debate about Plato's attitude to treating artifacts as having Forms (see Fine 1995, chapter 6), but I will focus on the more neutral sense that there is something that beds 'are', and I read Plato's comments in this light. A representation, such as a painting of a bed, is 'sort of' [tropoi] a bed-it is the appearance of one. A craftsperson makes something that concretely is a bed, manifesting what a bed is in a specific instance. But this is not to make that which a bed is $[h o$ 
esti klinē $].^{7}$ The notion of what a bed is is presupposed, at least in general, in the making of a particular item that is a bed. While a craftsperson might merely copy an existing bed (or a representation of a bed), in general we may suppose that they are guided by their understanding of what a bed is, an understanding that will derive from what a bed is used for. This, in the way I am construing it, is to understand what the Form of a bed is (see Frede 1999, 204ff.; Thomas 2014, 183f.). Similarly, a carpenter making a shuttle may be guided by the Form of a shuttle, 'the thing itself which is a shuttle' [auto ho estin kerkis]; for an item to possess the Form of a shuttle is for the item to be made in such a way that it is able to perform the work that shuttles are used for (Cratylus 389a-c). There is a sense in which the Form indicates in the most 'real' way what a bed or shuttle is (cf. how we may speak of what something 'really' is). ${ }^{8}$ This connects with a shift in focus from the particular manifestation (the 'sensible') to the intelligible: we get to what is most true of a thing by approaching 'the object with thought alone', which we use to 'track down each reality pure and by itself [auto kath' hauto]' (Phaedo 66a). ${ }^{9}$

The phrase 'what is F' is ambiguous. Two interpretations are readily available (Adomello 2013 mentions others). One corresponds to the case where, in asking 'What is hot?', we are looking for an answer as to which item happens to be hot (e.g. 'That radiator'). A second interpretation is where we are looking for an answer as to what hotness consists in. Adomello argues that the former is Plato's more likely usage, indicating the particular Form that constitutes a given characteristic. But Adomello allows that there may also be hints of the latter reading, in which the focus is on what characterizes a given Form. In particular, Adomello suggests that to know a Form is 'to know what it is for something to be $F$ ' (p. 63; the same suggestion is found in Nehamas 1979, p. 95; Sedley 2007, p. 84). Plato also, in many passages, expresses unambiguous focus on what characteristics constitute something's being such-and-such (cf. Politis 2010). He speaks of what any given thing 'actually is' [ho tunchanei hekaston on] (Phaedo 65d-e). He asks 'what is [pot' estin] imitation' (Republic X $595 \mathrm{c}$ ) and speaks of knowing what sight or hearing is [pot' estin opsis ... akoē] (Laches 190a). Sometimes the relevant characteristics are described or implied. He attempts in the Republic to explain what it is for a state, or soul, to be just (each part does its proper job). Knowledge [epistemēe], on one account, is 'to know, concerning what is, how it is' [to on gnōnai hōs echei] (Republic V 478a). We are said to know what the 'equal itself' is [epistametha auto ho estin] (Phaedo 74a-b), and this clearly corresponds to knowing what it is for two things to be equal (viz. as neither exceeding nor being exceeded by one another; see Sedley 1998, p. 128 for this suggestion). Speed is 'the power of accomplishing a great deal in a short time' (Laches 192b); shape 'is that which limits a solid' (Meno 76a).

It is one thing to note Plato's interest in what something is, another to give it plausible application and articulation. I will proceed by making a suggestion that, though mostly no more than hinted at in Plato, is supported by his discussions of Forms.

The first part of the suggestion is that we can plausibly apply the theme of knowing 'what something is' to the topic of linguistic understanding: to understand a word can be construed in terms of knowing how something, or some situation, has to be in order for the

\footnotetext{
7 '[Plato] distinguishes ho esti kline, the Form of Bed or what a bed is, from klinēn tina, some particular bed, which the carpenter builds' Prior 1983, 35.

${ }^{8}$ This corresponds to treating apparent 'self-predication' (the Form F is itself F) as meaning that the Form F is what it is to be F (see Nehamas 1979; White 1992; Silverman 2002).

${ }^{9} \mathrm{I}$ here interpret 'itself by itself' as indicating a focus just on the Form rather than on a sensible that manifests the Form. Cf. Parmenides 129a-d.
} 
word to apply. As Plato comments, 'Do you think that any one can understand the name of a thing when he doesn't know what the thing is [ti estin]?-No, certainly not' (Theaetetus 147b). ${ }^{10}$ I do not need to know that a speaker, in a given instance, means 'in five minutes' by 'immediately' in order to count as competent with English. I do, though, need to have a grasp of what immediacy is, or of what an emergency is, and so on-or at least I take this to be a valid intuition, albeit one that is not usually expressed by theorists working on word meaning. Other examples can help elicit this intuition. We use 'because' when we wish to convey that an explanatory relation holds and 'cause' when we wish to convey that a causal relation holds. While metaphysical or scientific insight into cause or explanation is presumably limited, I would find it harsh to be required to deny that there is an explanatorily important sense in which competent users of 'because' and 'cause' know 'what it is' that constitutes an explanation or a cause.

This last example and, more generally, the intuition that we really do understand the words we use, even without metaphysical insight, suggests that we need not construe the task of articulating word understanding in terms of an account aimed at providing a scientific or metaphysical appraisal of how items or relations are constituted. Here my focus diverges somewhat from Plato's demanding conditions on understanding and knowledge. I am taking it that there is an appropriate sense in which our everyday appreciation of a word not only underpins our use of words but also provides us with an understanding of what emergencies, causes, explanations (and so on) are, even if this is not an understanding that provides us with a metaphysically or scientifically informed analysis. (Cf. Chomsky 2000, who relates knowledge of language to our everyday human concerns and distinguishes this from the type of inquiry relevant to scientific investigation. Bostock 1994 makes a similar point.)

But how can we flesh this out into a more concrete proposal? I propose that we look to simple and recurring commonalities in how we relate to items and situations or in how items and situations relate to one another. The motivation for this is threefold: (i) the type of regularities I will describe are part of our shared everyday interaction with items, so they provide a plausible basis for a common understanding of the words we use; (ii) the regularities do not depend on common ingredients; (iii) the regularities can plausibly be associated with the Forms.

The general thought has already been illustrated in the (partial) explanation offered for our use of 'large'. Rather than looking to a large-making ingredient, the relevant explanation looks to the presence of a situation that displays the relation of exceeding. This is a relation between items that we share an understanding of and which, unlike explanations based on material or efficient causes, captures at least something of our everyday intuition as to what it is to be large.

\footnotetext{
${ }^{10}$ The Cratylus may seem the obvious text to appeal to, but there is reason to doubt its relevance. In the Cratylus, Plato does say that there is something about a word that 'fits' it to what we apply it to. He says that 'the ousia of the thing ... is exhibited [déloumenē] in its name' (393d), and he speaks of the expert name-giver as the one who can 'put [a thing's] form into letters and syllables' (390e; cf. 422d). On the other hand, perhaps partly in virtue of wanting to align what is 'exhibited' with the actual letters and syllables used, Plato often in practice describes merely typical characteristics of items rather than a putative Form as such. For example, the sun might be called hēlios because the sun 'collects' [halizein] people together when it rises. Plato offers other options for 'sun', showing that he was not thinking here in terms of a single Form of the sun (408e-409a).
} 
The point can be illustrated with other words. ${ }^{11}$ Consider 'obstacle'. Many things can be obstacles, but we do not apply 'obstacle' on the basis of a shared ingredient that we discover possessed by all items that are obstacles. Rather, being an obstacle pertains to manifesting a relation of prevention (typically of movement) to something else. It is this role as a preventer that licenses use of the term 'obstacle'. Given the variety of things that move and the variety of ways in which they move, the items that prevent movement will also vary enormously. Bumps in the floor prevent marbles from progressing; anti-tank constructions prevent movement of armoured vehicles. For both cases, this licenses use of the word 'obstacle' and so licenses the ascription of the property of being an obstacle to small bumps and large barriers. The ascription is based on 'something in common', but this commonality is not conceived in terms of a shared ingredient. Rather, it relates to a relation of prevention manifested between a potentially moving item and another item.

I take this role as a preventer to correspond to a basic intuition as to what obstacles are. While an answer to the question 'Why is that an obstacle?' can indeed be given in terms of the particular sensible characteristics of an item (it is made of concrete, it is thirty feet wide, and so on), there is also an answer to be given in terms of the role an item plays in preventing something else. I take it that it is this latter answer that corresponds both to the form of explanation that Socrates was interested in and to the appropriate form of explanation for how we understand a word.

Or consider 'open'. There are many ways in which things can be open, in the sense that the physical manifestation of the state of being open may differ across instances: bottles are open in one way, books in another, rooms in another. Particular things can be open in more than one way: a washing machine can be open in a way that allows clothes to be placed in the drum or open in a way that allows an engineer access to the motor. It hardly makes sense to suppose that there could be an explanatory common ingredient found across all ways of being open. But, arguably, we can describe a commonality that licenses the use of 'open': an item is open when it enables access, whether that is access to contents the item itself contains (as when a room is open) or to something else to which the item typically prevents access (as when a door is open). This characterization is neutral as to what the contents are, how they are contained, or the type of access that is required. Plausibly, this characterization relates to a basic understanding of what it is to be open.

The general suggestion can be further illustrated with respect to Harte's (2002) discussion of parts and wholes in Plato. Consider a dinner party (ibid. pp. 159-165). A dinner party is made up of guests. But for an item to be a guest is not for that item to possess an ingredient that constitutes it as a guest-as if to suggest that we could construct a guestcontaining situation by choosing items that, prior to that situation, already have the status of being guests. Rather, it is by virtue of belonging to the dinner party that the items attain guest status. The whole (the dinner party) has parts (the guests); but it is misleading to say that the whole is constructed from those parts given that the parts only have their status by virtue of the whole.

From this perspective, which Harte ascribes to Plato, wholes relate to structure, not to ingredients. Ingredients will be present where there is a whole and, for some forms of explanation, reference to those ingredients will be appropriate (as when we say 'It's an obstacle because it is made of concrete'). But there is another form of explanation for which the whole is prior to the parts, and this form of explanation is given not in terms of ingredients

\footnotetext{
${ }^{11}$ For a particularly interesting discussion of the word 'refinement' and, significantly, of Wittgenstein's example 'Spiel', see Hoyningen-Huene 2015.
} 
(even though the ingredients need to be appropriate for manifesting the whole) but in terms of a structure in which something occurs or that something helps to manifest. While obstacles and open items are not elucidated in terms of a wider structure in the same way that guests are in the dinner party structure, the role of preventer, or the status of providing access, does relate to a relational structure that is precipitated, so to speak, when the items play the role that they do. ${ }^{12}$

We can combine this with Harte's suggestion that discussion of form in the later dialogues can be associated with the structures that constitute a whole $(2002$, ch. 4$) .{ }^{13}$ I will generalize this by taking structure as a way to elucidate the notion of a Form (on associating Forms with structure, or abstract patterns, see also Prior 1983; Thomas 2014). That is to say, a Form is envisaged in terms of a specific functional or relational structure. Applied to a hypothesis about words, this is to say that to understand a word is to grasp the relevant structure. This will be a commonality across instances, such as the commonalities of prevention of movement or the enabling of access. The commonality can be described independently of the particular ways in which these structures are manifested in a given case. $^{14}$

Given this, we can develop an argument to explain why, in principle, general terms do not apply to items on account of shared ingredients. In the favoured sense of explanation, no item is an obstacle because of its ingredients. The ingredients only attain their status as ingredients of an obstacle when there is an explanation of the obstacle in terms of the whole, that is, in terms of the preventing-structure that the item helps to manifest. It is this type of commonality that corresponds to a Form and hence, by hypothesis, to what guides our use of 'obstacle'. Because wholes are conceived, primarily, in terms of structure and not in terms of a composition of parts, it follows that the explanatory basis for use of a general term will not be a criterion that looks to the parts with a view to determining a diagnostic that defines a putative class of instances. The explanatory value of the ingredients with respect to a predication is dependent on the whole that licenses the predication. Hence, the ingredients themselves are, in a sense, unseen by and irrelevant to the predication.

On this understanding of Forms, we see that an account of predication that draws from Plato's discussion is not only consistent with a lack of common ingredients between the items to which a general term applies, but it is also explanatory of why, in general, we would have no reason to expect commonality at the level of ingredients.

I conclude this section by noting some problems. Scientific terms and terms for species put pressure on associating word understanding with a knowledge of what something

\footnotetext{
${ }^{12}$ cf. McCabe 1994, pp. 224-234, who argues that, for the late Plato, relations between things are the context in which individuals appear. That is to say, we do not start with the kind 'obstacle' and then count items as individuated by that kind; rather, we start with a preventing relation that provides the context in which an individual obstacle appears. Individuation is 'relative to something's place among other somethings' (p. 231). From this perspective, we can see that the 'ingredients' of a thing are not the focus, though the possibility of playing a role in a structure will depend on having the appropriate ingredients.

${ }^{13}$ Health is a harmonious blend of elements in the body; music is some pertinent relation between the high/low, the fast/slow (Harte 2002, pp. 191-2). In similar fashion, justice is characterized in the Republic by the parts (whether of state or soul) doing their proper job, an account that enables Plato to explain how 'just' can apply, univocally, to both the state and the soul (Republic V 434a-c).

${ }^{14}$ By hypothesis, a Form is not identical with any instance nor with any collection of instances; and a Form may be thought of without thinking of an instance, in exactly the way we have been doing by speaking of 'preventer of movement'.
} 
is. I do not claim to have an account for such words and to some extent bracket them. This is not entirely arbitrary. Unlike most of the words we use, words such as 'elm', 'encephalitis', 'lepton' appear to act, at least to some extent, simply as labels for some stuff, or thing, about which we may, in varying degrees, be largely ignorant (cf. Millikan 2000). If so, there may be a principled reason for supposing that an account of such words will vary somewhat from an account of words such as 'large', 'obstacle', 'open' with which we display an easy familiarity. It is this latter type of word that makes up the vast bulk of our discourse (though in comparison with the 'label' type words, they have received little attention by philosophers).

Given the complexities of natural language, the specific suggestions that I have made for various words (with reference to exceeding, prevention, access) will always be susceptible to counter example. For example, for a suggested common structure, it may always be possible to think of situations that seem to fit the structure but where the word is not licensed. A peeled orange provides access to its contents, but we do not describe such an orange as 'open'. If we puncture a bicycle inner tube, we gain access to the air inside, but we do not describe this as an 'open' inner tube. ${ }^{15}$ Similarly, prevention does not distinguish obstacles from barriers, and not all types of exceeding license the use of 'large'. Further, there may be uses of a word that appear not to fit the proposed structure, as with 'The meeting is now open' or 'It is an open question'.

Responses to these problems can be offered, ${ }^{16}$ but I do not claim that the accounts are lexically complete as they stand-clearly, they are not. There are problems of implementation. I do not, though, see any reason to suppose that these problems make it likely that the account is wrong in principle.

\section{The compresence of opposites}

When we apply a term ' $F$ ' to an item, we may also ascribe the property of being $F$ to that item. If we take this to indicate that the item is in part constituted by an element that licenses the use of ' $\mathrm{F}$ ' and that is required for this use, we seem to be committed to an account in which there will only be one answer to the question of whether ' $F$ ' can be correctly used of an item: if the appropriate element is present, we can correctly use ' $F$ ', otherwise not. Plato observes that how we describe items does not always follow a pattern consistent with this picture. An item that we correctly describe as large can also correctly be described as small or not large: a large ant is not a large creature (cf. Phaedo 102b-d; Republic 479b). Similarly, an item we describe as beautiful may also be described as not beautiful. In the Symposium, a contrast is made between the Form of beauty and beautiful things:

\footnotetext{
${ }^{15}$ Thanks to Jeffrey King for the orange example and Michael Glanzberg for the puncture example.

${ }^{16}$ In response to the orange, we can argue that our sense of what is linguistically acceptable is influenced by the presence of competing more specific vocabulary ('peeled') — see Blutner 1998 for lexical blocking. Further, we would not say that a person misunderstands 'open' if they apply it to an orange (the fact that we would not say this, in spite of the fact that it is not an established usage, is highly significant). In response to the puncture, we can say that the notion of puncturing does not focus on access to the contents. Where we do have such interest, we may say 'I opened it by puncturing it', though not all puncturings are openings. For 'It is an open question' we may appeal to polysemy. Emphasis on a shared intelligible is intended to indicate the structure that informs our understanding of a particular sense; there is no entailment that words only have one sense.
} 
it [the Form of beauty] is not beautiful in one respect and ugly in another, or beautiful at one time and not at another, or beautiful by one standard and ugly by another, or beautiful in one place and ugly in another ... . (Symposium 211a; cf. Hippias Major 289b-c; Republic V 479a-b)

Beautiful things, by contrast, do vary in these respects. What is beautiful in one setting, or time, or place, may not be regarded as so in another. Plato makes a similar point for 'equals', albeit in an over-compressed passage that is open to a range of interpretation (see Sedley 2007): equal sticks and stones 'while remaining the same, appear to one [tō(i) men] to be equal and to another $[t \bar{o}(i) d e]$ to be unequal' (Phaedo 74b). Using the Symposium passage as a guide, I take the general point to be that even when we can properly describe two sticks as 'equal' to one another, there may also be many contexts in which we would not describe those two sticks as equal to one another. This might be because there are different respects in which the sticks may or may not be equal (in length, width, weight, and so on); or maybe we apply different standards of measurement (for the purposes of building a fence, two sticks will count as equal even if, for the purposes of precise scientific measurement, they are unequal); perhaps Plato also envisages cases where we take one of the sticks and compare it to another stick (cf. Republic X 602d-e; Sedley 2007 rejects this option). ${ }^{17}$ Similarly (see Republic 479b, 523e) doubles can be seen as halves (4 is double 2 and half 8 ); anything heavy can also be called light; what is thick can also be described as thin, what is hard can also be described as soft (hard cheese is soft compared with metal): 'they will always have something of both in them' (Republic V 479b).

If the immediate perceptible properties of an item are constant, we cannot straightforwardly appeal to the sensible properties in order to explain the compresence of opposites. A further explanation is required, and Plato will appeal to the 'intelligible' as that which fills this gap. Plato does not suppose that this phenomenon is entirely general. There is no instance, for example, 'where our sight indicates that a finger is at the same time the opposite of a finger' (Republic VII 523d; cf. Parmenides 130c-d). But where it does apply, explanation is needed. Following a suggestion from Harte, I will take Plato's observation on the compresence of opposites, not as indicating a limit to the extent of the Forms (as if Forms are only required in cases where compresence is found), but as indicating a puzzle that any account needs to satisfy and that cannot be explained merely in terms of perception of sensibles (Harte 2011, pp. 200-1, 205).

The compresence of opposites is consistent with basing word use on the kind of commonality that I sketched in the previous section. An ant may exceed the typical ant in size and thereby be described as 'large', while also vastly failing to exceed many other living creatures and thereby be described as 'small'. What prevents movement, and thereby counts as an obstacle, when we are walking-a brick wall, for example-will not count as an obstacle if we are in a tank. A washing machine counts as open for the laundry person if it

\footnotetext{
${ }^{17}$ McCabe comments: 'Is Plato making a point about (1) relativism (everyone's view of a given pair of sticks is different); (2) the imperfection of the physical world (any given pair of equals will not be equal in every respect); or (3) the structure of the phenomenal world (any stick is involved in relations of both equality or inequality)?' (1994, p. 41). McCabe suggests Plato subscribes to all three but with a focus on (3), which she also describes as particulars being 'naturally contextualized within their world' (p. 44, cf. n. 12 above). There is an alternative text (reading tote men ... tote de instead of tō(i) men ... $t \bar{o}(i) d e$ ) 'equal at one time and not at another', which McCabe sets aside as of doubtful conceptual worth.
} 
provides appropriate access to the drum, but this might not count as open for the engineer who requires access to the motor. Because the commonality relates to a relational structure, and the same item can play a role in different instances of such structures or instances where the structure is not manifested, we have a natural explanation for the phenomenon of the compresence of opposites. In the context of a given instance, an item may truly be an obstacle (because it prevents) or may truly be open (because it provides access), though the same item, in the same state, may in different contexts truly be described as not being an obstacle or as not being open.

Distinctions drawn in terms of ingredients would portion items into determinate extensions independently of the kind of relational structures that I have spoken of. If an ingredient is a mark that defines all and only members of a class, an item will be classified as a member of this class if it possesses the relevant ingredient, and not otherwise. The phenomenon of the compresence of opposites suggests that, as a general account, predicates do not pick out extensions determined by such classifying marks. The point is suggestively indicated by the evident way in which perhaps anything, in the appropriate context, could be correctly described as large or as an obstacle, or correctly described as not large or not an obstacle. The examples show that words, to be useful, do not need to be oriented to determining extensions on the basis of the kind of classifying marks that would determine that an item is either in, or not in, a particular grouping. But the examples also show that this does not preclude there being a common basis for the use of a predicate, upon which a judgement of truth or falsity may be made.

\section{Participation in Forms: degrees of approximation?}

We may describe a table as flat and a bowling green as flat. A table will typically be flatter than a bowling green. Does it follow that the word 'flat' relates less precisely to the bowling green than to the table, with some kind of degeneration in evidence with respect to how 'flat' relates to less flat items in comparison with very flat items? That is to say, does 'flat', when considered strictly, properly mean a perfectly flat surface, even though, in linguistic practice, we also apply it to surfaces that are often far from perfectly flat? There is an obvious way in which we can use predicates inaccurately. I speak inaccurately if I describe as flat a bowling green that has a mound in it. But suppose we stick to uses of a predicate that are regarded as accurate. We can still ask whether the predicate fits some of those uses better than others. For example, if two surfaces are smooth, we speak accurately, according to ordinary intuitions, if we describe both surfaces as smooth. Suppose, though, that one of those surfaces is smoother than the other (which, after all, will be the typical case). Do we want to say that the word 'smooth' fits the smoother item better than the less smooth item?

Plato's account allows words to either apply, or not, without there being degrees of accuracy with which the word applies to an item. I take this to be a desideratum of a theory of word meaning. In spite of the apparent plausibility of the suggestion that words such as 'flat' apply with differing degrees of 'looseness' depending on how close to a geometrical plane a surface comes (see e.g. Carston 2002, section 5.1.2), this is a picture that has no obvious application for many words.

Consider 'open'; there is little or no motivation to suggest that some open items, or some ways of being open, are more precisely examples of being open than others. It would be odd to say that an open bottle is a better or worse example of being open than an open book, 
or that a more widely open door is closer to the meaning of 'open' than a less widely open door. The point here is not to deny gradability of predication. A large ant is less large than a whale. The point, rather, is that there is motivation to deny gradability in truth. ${ }^{18}$ To say, of an appropriate instance, 'That ant is large' is as true as to say, of an appropriate instance, 'That whale is large'. The correctness with which 'large' or 'open' is applied need not, in general, differ, even if there is also a way in which we can compare the scale of largeness or the wideness of being open across the several items that have been correctly described as large or open.

This also seems to be the way that Plato thinks of the relation between things and Forms, though the point is not beyond dispute. Nehamas (1975) notes several texts where Plato speaks of particulars as falling short of, or being inferior to, the Forms that they participate in. ${ }^{19}$ For example, there is 'considerable deficiency' [ $p$ olu ... endei] with respect to how equal sticks are equal in comparison with how the 'equal itself' is equal (Phaedo 74d). This may suggest an interpretation in which equal sticks vary with respect to how close they approximate to some ideal exemplar of equality, and Nehamas notes that many scholars have in fact expressed something like this view.

The context of Plato's discussion, though, suggests an alternative interpretation (for the following, see Nehamas 1975; White 1992; Silverman 2002; Rowe 1993; Harte 2011; Adomello 2013), and Nehamas, for example, claims that, for Plato, 'particulars participate in the Forms in different respects or in different contexts, but never, so far as I can tell, in different degrees' (Nehamas 1975, p. 110). The deficiency that particulars display relates to their being distinct in type from the Forms themselves. Particulars suffer from the compresence of opposites: an item may be beautiful in one respect but not in another, or beautiful from different perspectives, or, due to change, be beautiful at one time and not at another. These characterize a form of deficiency that is not found with the Form itself. A Form is changeless. A Form, as I have expounded it, corresponds to a relational structure and from no perspective does it ever not correspond to that structure.

Rather than speaking in terms of degrees of participation in a Form, Plato speaks of sameness with respect to how items compare in respects of having a particular general term truly applied to them. If two items are described with the same word (such as 'large'), this indicates that the two items are like each other in the respects in which that word was used of those items (Republic V 435a). A just man 'will not differ at all [ouden dioisei] from a just city in respect of the very Form of justice, but will be like it' (ibid., 435a-b). Bees do not differ [ouden diapherousin] from one another in being bees (Meno 72b). The strength of a man and a woman will be the same: 'that strength will be the same and have the same Form, for by "the same" I mean that strength is no different as far as being strength [ouden diapherei pros to ischus einai he ischus] whether in man or woman' (Meno 72e). Different shapes (round, square, etc.) all equally participate in that which shape is: 'the round is not more a shape [ouden mallon ... schèma] than the straight' (Meno 74d). Different multitudes differ in size, but Plato at no point indicates that the greater a multitude the greater the degree of participation in 'multitude' (see Parmenides). Hippias Major distinguishes the question of whether a pleasure is greater or smaller, more or less [meizōn ... e elattōn e mallon e hêtton], from whether something differs 'in this very way-in being a pleasure [tō(i) he men hédone einai]' (299d). The latter is denied, this being consistent with differing degrees of pleasure.

\footnotetext{
${ }^{18}$ Thanks to Peter Sutton for suggesting this way of expressing the point.

${ }^{19}$ Phaedo 74d; 75a-b; Symposium 210e-212a (on true beauty); Republic 515d; Phaedrus 247c; Philebus 59d.
} 
Taking up the suggestion from section 2 (following Harte), participation conceived in terms of manifesting a status that is in part constituted in terms of a relation to other itemssuch as exceeding the other items, or preventing movement, or enabling access-provides an account of how sensible items can relate to a Form without degrees of approximation. An ant can be large because it exceeds ordinary ants in size. The ant thereby, and not by matter of degree, manifests a condition that can be described as a participation in the Form of the large. The ant from other perspectives is not large; and the ant, at one stage of its existence, may not have been large even from the ant perspective. In this way, the ant is deficient with respect to the Form of the large, but this does not mean that the ant only participates in the Form to a small degree. A blue whale is deficient with respect to the large in the same way that an ant is, and yet both fully participate in the Form. Or consider what it is to be an obstacle. If the Form of an obstacle relates to prevention, a brick wall that prevents movement participates fully in the obstacle Form. This participation is not by matter of degree, as if a cliff were taken to participate more fully in the obstacle Form because the cliff prevents more types of motion. Differing degrees of prevention are consistent with the preventing items all equally participating in the Form. The deficiency of the wall is exactly the same as the deficiency displayed by a cliff: they are not always obstacles (sometimes they can be precisely that which enables movement, as when we stand on a cliff or wall and jump).

The picture presented here is consistent with the emphasis described in sections 1-3. We are not, when considering a Form, looking to a sensible instance, with respect to which a 'degree of participation' account would be a natural corollary given that there are varying degrees of resemblance to an exemplar. Exemplars are instances, whether ideal or otherwise, but it is precisely the appeal to instances that Socrates takes as inadequate for an answer to the 'what is F' question (and treating a Form merely as an 'invisible' instance does not make up for the explanatory inadequacy). ${ }^{20}$ Rather than looking to degrees of likeness to an instance, the picture I have drawn from the Forms is one in which we look to a notion of what something is. For being large, open, or an obstacle, I have suggested that we can understand these states in terms of exceeding, enabling access, or preventing movement. This is explanatory for how instances that vary considerably from one another can equally participate in the Form, given that the manifestation of these states is not determined by the presence of common ingredients.

\section{Criticizing Wittgenstein}

I have focused on an 'ingredient' perspective for the putative commonality that Wittgenstein rejects, and I have suggested that Wittgenstein's comments can be reconciled with, and

\footnotetext{
20 'Any attempt to conceive of the forms as perfect particulars ... is problematic almost to the point of being nonsensical ... [W] hat in the world could a quintessential instance of largeness, or humanity, be like?' (Adomello 2013, p. 53). Perhaps the regress argument given at Parmenides 132a-b can be treated as a reductio of the supposition that a Form 'appears' to the 'mind's eye' in a fashion analogous to being perceived. Socrates then suggests that Forms are 'as if patterns set in nature [hōsper paradeigmata hestanai en tê( $(i)$ phusei]', with participation in a Form meaning 'nothing other than being modeled on them [eikasthēnai autois]' (132d). Parmenides puts pressure on this by arguing for a regress derived from a consideration of 'likeness'. These passages indicate a doubt over a construal of 'participation' in terms of likeness to a paradigm instance (perceived in some inward fashion). There are other ways to construe the idea of being modeled on a pattern.
} 
explained by, an appeal to the Forms. But why suppose that Wittgenstein limits the notion of something in common to the type of characteristic that fits the ingredient image? Might his claim be that any proposed commonality will, in the end, prove unable to account for how we use a general term ${ }^{21}$

In practice, Wittgenstein limits himself to looking for ingredient-style characteristics, those specific elements that are found in the instance of which they are a part. In his discussion of 'Spiel' (game, play), for example, he briefly considers whether instances display characteristics such as winning and losing, or competition, or amusement (1953, §66). He does not consider commonalities where the focus is on an over-arching structural or relational characteristic that provides the constancy of focus appropriate to the 'what it is' and that is associated with the Forms.

One possibility is that this is simply an oversight in how Wittgenstein illustrates his concern, and that he would wish to apply his criticism to any level of commonality. There are two concerns with this, which I mention below. But first, it is also possible that the limitation in the kind of commonality considered is integral to Wittgenstein's discussion of language.

The overall context in the Investigations is that of showing that how a word is usedand this may include specifying the items to which the word is truly applied in a given usecannot be determined by some putative 'meaning' that we might formulate in terms of an explanation or definition. The explanations or definitions may help guide our use of a word (see e.g. 1953, $\S 50-55$ ), but they do not actually fix how we use the word (see e.g. 1953, $\S \S 28-34,53,139-141)$.

However, suppose that it is possible to find a common ingredient across a set of items that fall under a given predicate. In principle, this would allow for a determinate diagnostic for defining a group of items to which a given term could truthfully be applied. The term need simply be correlated with those ingredients, and further considerations of use need not enter an account of what constitutes the extension of the term. This would undermine Wittgenstein's claim that there is an element of decision, in our use of a word, that cannot be fixed beforehand. Hence, Wittgenstein illustrates the implausibility of there actually being the required common ingredients.

The crucial point here is that the type of commonality that I have associated with a Form need not be such as to determine usage. This is one of the lessons of the 'compresence of opposites'. A Form need not provide us with the kind of definition that establishes decisively whether or not an item falls under a predicate. It follows that this might not be the type of commonality that Wittgenstein was concerned to deny.

On the other hand, neither can it be ruled out that Wittgenstein would have countenanced extending his rejection of a commonality even to the kind that I have associated with the Forms. This, though, would lead to two problems, the second of which is specially pertinent to a discussion of Plato.

The first problem is that it makes the status of Wittgenstein's positive account as to why certain groupings occur, as marked by general terms, very unclear. Appeal to crisscrossing resemblances and relations seems to leave us with no interesting or plausible constraints on what may count as a member of a particular group (Richman 1962; Griffin 1974). We would expect amorphous groupings of disparate items, with new members arising

${ }^{21}$ Thanks to a referee for raising this concern. 
simply on the basis of some unspecified resemblance to some one or other previous member of the group. This is not a promising picture. ${ }^{22}$

The second problem relates to intelligibility. If there was no commonality, nothing corresponding to our grasp of a word besides the practice of using the word for such-and-such items, there would be no place in our explanation for something that provides, for the understanding, the knowledge of 'what it is' (as discussed in section 2). Arguably, this concern is expressed by Plato's Parmenides. If a person gives up on the existence of Forms,

he won't have anywhere to turn his thought, since he doesn't allow that for each thing there is a character that is always the same. In this way he will destroy the power of dialectic entirely (Parmenides 135b-c).

Commentators note that 'dialectic' here could have a general everyday sense of 'dialogue, conversation'. If this non-technical reading is correct, this passage would show a link between the Forms and the very possibility of linguistic communication (and see Theaetus 147b, noted in section 2; Bostock 1994). A link is compelling: knowledge of an alignment between a word and an extension does not constitute any grasp of a 'what it is', and yet it is just such a grasp that appears to characterize our everyday understanding of the words we use.

The reference in the passage to something that is 'always the same' corresponds to the changeless nature of the Forms. A significant, though often overlooked, linguistic parallel clearly presents itself: while our understanding of the things and situations that words are used to speak about is forever changing, there is much less motivation to suggest that there is any corresponding growth or change in our understanding of the words themselves. For example, my understanding of engines is always open to change, while my understanding of the word 'engine' appears to be a fixed point-possibly largely fixed since I first comprehended the word. Of course, there are some caveats here. Some types of polysemy are learnt over time, and we can have mistaken understandings. But there remains a secure intuition that we have a fixed, and completely adequate, understanding of most of the words we use.

While theorists may mention that we need accounts of language change, we also need an account of how words display constancy of meaning over centuries. Examples listed in the Oxford English Dictionary indicate that we can trace back a contemporary sense of 'emergency' 300 years, 'engine' 400 years, 'large' 500 years, 'obstacle' 600 years, 'open' 700 years. What is constant enables us to understand discourse from centuries ago, though we may be confused about the kind of engines (for example) that were being spoken about. To put this another way, there is nothing about our understanding of most words that needs to change, even if there is considerable change in the items those words are used to speak about. Arguably, this constancy is a corollary of the basic requirements for the possibility of linguistic understanding.

\section{Conclusion}

Plato's account of the Forms provides an explanation for why a predicate may apply to items that display 'many manifestations [phantazomena polla]' (Republic V 476a), that vary in

\footnotetext{
${ }^{22}$ Gert 1995 argues that Wittgenstein did not suppose that 'resemblances' form the basis of a grouping, and I agree that this need not be the way we construe Wittgenstein's introduction of the 'family resemblance' point—but neither is it clear that this would be an incorrect construal.
} 
'every sort of way [pantoiōs]' (ibid. VI 484b), and can be 'in some way even quite unlike each other', even 'contrary' [enantias] to each other (Philebus 12c, 13a). It offers us an approach to word meaning that is consistent with a lack of determinacy in use, and yet which does not take the Wittgenstein inspired route of abjuring a fixed, changeless point in our account of what it is to understand a word. Rather, we retain a place for a constant element in our thought that both corresponds to a grasp of 'what it is' and, arguably, plays the central role in what is involved in understanding a word.

\section{Bibliography}

Adomello, F. 2013. Plato's conception of the forms: some remarks. In R. Chiaradonna and G. Galluzzo (eds), Universals in Ancient Philosophy, pp. 41-86 (Edizioni della Normale, Pisa). Bostock, D. 1986. Plato's Phaedo (Oxford: Clarendon Press).

Bostock, D. 1994. Plato on understanding language. In S. Everson (ed.) Companions to Ancient Thought 3: Language, pp. 10-27 (Cambridge: Cambridge University Press).

Blutner, R. 1998. Lexical pragmatics. Journal of Semantics 15:2, pp. 115-162.

Carston, R. 2002. Thoughts and Utterances (Oxford: Blackwell).

Chomsky, N. 2000. New Horizons in the Study of Language and Mind (Cambridge:

Cambridge University Press).

Fine, G. 1995. On Ideas: Aristotle's Criticism of Plato's Theory of Forms (Oxford: Clarendon Press).

Forster, M. 2010. Wittgenstein on family resemblance concepts. In A. Ahmed (ed.)

Wittgenstein's Philosophical Investigations: A Critical Guide, pp. 66-87 (Cambridge:

Cambridge University Press).

Frede, D. 1999. Plato on what the body's eye tells the mind's eye. Proceedings of the Aristotelian Society 99, pp. 91-209.

Gert, H. 1995. Family resemblances and criteria. Synthese 105:2, pp. 177-190.

Griffin, N. 1974. Wittgenstein, universals and family resemblances. Canadian Journal of Philosophy 3:4, pp. 635-651.

Harte, V. 2002. Plato on Parts and Wholes: The Metaphysics of Structure. Oxford: Clarendon Press.

Harte, V. 2011. Plato's metaphysics. In G. Fine (ed.) The Oxford Handbook of Plato, pp. 191-216 (Oxford: Oxford University Press).

Hoyningen-Huene, P. 2015. A note on the concept of game (or rather Spiel). In G. Betz, D.

Koppelberg, D. Löwenstein, A. Wehofsits (eds) Weiter denken - über Philosophie,

Wissenschaft und Religion, pp. 205-210 (Berlin: de Gruyter).

Ide, H. 2002. Complex property structure in Plato's Philebus. Ancient Philosophy 22:2, pp. 263-276.

Irwin, T. 1995. Plato's Ethics (Oxford: Oxford University Press).

McCabe, M. M. 1994. Plato's Individuals (Princeton, New Jersey: Princeton University

Press).

Millikan, R. 2000. On Clear and Confused Ideas (Cambride: Cambridge University Press).

Moravcsik, J. 1990. Thought and Language (London: Routledge).

Nehamas, A. 1975. Plato on the imperfection of the sensible world. American Philosophical

Quarterly 12:2, pp. 105-117. 
Nehamas, A. 1979. Self-predication and Plato's theory of forms. American Philosophical Quarterly 16:2, pp. 93-103.

Pietroski, P. 2005. Meaning before truth. In G. Preyer and G. Peter (eds) Contextualism in Philosophy, pp. 255-302 (Oxford: Clarendon Press).

Politis, V. 2010. Explanation and essence in Plato's Phaedo. In D. Charles (ed.) Definitions in Greek Philosophy, pp. 62-114 (Oxford: Oxford University Press).

Prior, W. 1983. The concept of paradeigma in Plato's theory of Forms. Apeiron 17(1), pp. 33-42.

Recanati, F. 2004. Literal Meaning (Cambridge: Cambridge University Press).

Recanati, F. 2010. Truth-Conditional Pragmatics (Oxford: Clarendon Press).

Richman, R. 1962. "Something Common". The Journal of Philosophy 59:26, pp. 821-830.

Rowe, C. 1993. Plato: Phaedo (Cambridge: Cambridge University Press).

Sedley, D. 1998. Platonic causes. Phronesis 43:2, pp. 114-132.

Sedley, D. 2007. Equal sticks and stones. In D. Scott (ed.) Maieusis: Essays in Ancient Philosophy in Honour of Myles Burnyeat, pp. 68-86 (Oxford: Oxford University Press).

Silverman, A. 2002. The Dialectic of Essence: A Study of Plato's Metaphysics (Princeton: Princeton University Press).

Thomas, C. 2014. Plato on metaphysical explanation: does 'participating' mean nothing? Studia Philosophica Estonica 7(2), pp. 168-194.

Vlastos, G. 1969. Reasons and causes in the Phaedo. The Philosophical Review 78:3, pp. 291-325.

White, N. 1992. Plato's metaphysical epistemology. In R. Kraut (ed.) The Cambridge Companion to Plato, pp. 277-310 (Cambridge: Cambridge University Press).

Wittgenstein, L. (1953). Philosophical Investigations (Oxford: Blackwell).

Wittgenstein, L. (1972). The Blue and Brown Books (Oxford: Blackwell).

Wolfsdorf, D. (2003). Understanding the 'What is F?' question. Apeiron 36, pp. 175-188. 